\title{
STRATEGI KOMUNIKASI PERSUASIF RASULULLAH SAW TERHADAP KAUM PEREMPUAN (STUDI ANALISIS HADITS
}

\section{TARBAWI)}

\author{
Wawan Trans Pujianto \\ Institut Agama Islam (IAIN) Negeri Metro \\ Jalan Ki. Hajar Dewantara 15A Iringmulyo, Metro Timur, Kota Metro \\ email:trans@metrouniv.ac.id
}

\begin{abstract}
The tendency of women at the moment who are preoccupying themselves with worldly matters needs to be guided by the right and right direction in dealing with the current hedonism that continues to rule so that the tendencies of these women can gradually be changed for the better. Therefore, it is necessary to know how the success of persuasive communication carried out by the Messenger of Allah sallalahu 'Alaihi Wasallam against women (Shahabiyah) so that it can be applied in the present.
\end{abstract}

This paper basically aims to find out a theoretical study of the persuasive communication of the Prophet Muhammad towards women from the perspective of tarbawi hadith as well as knowing what causes the failure to indict women. In an effort to obtain secondary data to compile a theoretical and conceptual framework by examining primary materials such as the Women's Assembly book, Messages and Testaments of the Messenger of Allah to Women, Women Asking the Prophet Answering, Arba'in AdDa'awiyah, Examples of the Application of the Messenger of the Prophet.

From the analysis studies it can be concluded that in giving enlightenment to women of the importance of shari'ah science it is necessary to use a good strategy so that they easily accept the invitation. Just as in dealing with women in the process of preaching there must be a lot of dialogue not just a monologue, showing empathy, touching emotions and feelings because the target of preaching to women lies in their emotions and feelings, giving satisfactory answers to various issues raised, in preaching to the people women must be able to adjust between time and place to deliver material so that preaching is easy to accept, giving opportunities to women to dialogue in the form of questions or outpouring of hearts, giving an impression and strong motivation for commitment to religion.

Keywords : Strategy, Persuasive, Communication, Women, Tarbawi Hadith 


\section{A. Pendahuluan}

Melihat sebuah keberhasilan Rasulullah Shallalahu 'Alaihi Wasallam dalam mendakwahi kaum perempuan (shahabiyah), yang mana jika dilihat secara historis bukan hanya Rasulullah saja yang menginginkan supaya dakwah itu bisa tersampaikan kepada mereka, akan tetapi juga didorong dengan keinginan yang kuat dari jiwa mereka untuk menggali ilmu agama.

Eksistensi perempuan dalam kehidupan masyarakat diakui sebagai bagian dari rahmatan lil 'alamin. ${ }^{1}$ Kemajuan dan kemunduran generasigenarasi Islam tidak terlepas dari kaum perempuan. Kaum perempuan adalah bagian terbesar dari masyarakat. Mereka juga memiliki peran dan pengaruh yang sangat besar dalam mengarahkan kaum laki-laki dan mencetak generasi baru.

Namun seiring dengan perkembangan zaman yang serba modern ini, kaum perempuan semakin banyak yang lupa akan jati dirinya sebagai sosok yang memiliki figur yang sangat penting di dalam kehidupan bermasyarakat terlebih lagi ketika sudah menjadi seorang Ibu rumah tangga, yang mana peran Ibulah yang menjadi patokan berhasil tidaknya pendidikan yang diberikan untuk generasi-generasi penerusnya, bahkan semakin banyak kesibukan-kesibukan yang mereka perbuat sehingga tugas utamanya justru terabaikan. Maka wajar kalau mereka (kaum perempuan) terutama yang sudah berkeluarga yang menyibukkan diri dengan berbagai kegiatan mereka gagal dalam mendidik anak.

Pada masa sekarang ini banyak kaum perempuan yang fobia ${ }^{2}$ terhadap ilmu-ilmu agama, mereka menganggap ilmu agama sebagai sampingan saja, bahkan anggapan mereka yang lebih penting adalah bagaimana bisa bekerja dan menghasilkan uang. Padahal sabda Rasulullah Shollallohu 'Alaihi Wasallam diatas memberikan peluang bagi kaum perempuan untuk dapat memperdalam ilmu-ilmu agama guna mencari bekal menuju kebahagiaan dunia dan akhirat.

Oleh karena itu menjadi sangat penting bagi kita untuk mengatahui bagaimana strategi komunikasi persuasif Rasulullah Shallallahu 'Alaihi Wasallam terhadap kaum perempuan sehingga menjadi menarik dan mudah diterima oleh mereka.

1 Nurdin A. Fauzie, Perempuan Islam dan Transformasi Sosial Keagamaan, Yogyakarta : Gema Media, Cet I, 2009, h.31.

${ }^{2}$ Kecenderungan perasaan seseorang yang ditandai rasa takut yang berlebih-lebihan, sekalipun obyek ditakuti tidak ada alasan jelas. 


\section{B. Metodologi}

Penelitian ini merupakan penelitian kepustakaan dengan menggunakan metode pendekatan kualitatif historis. Pendekatan kualitatif historis ini dimaksudkan untuk menganalisis sebuah tindakan yang dilakukan pada masa lalu secara sistematis dan obyektif. Adapun yang menjadi fokus pembahasan dalam penulisan ini yaitu terkait strategi komunikasi persuasif dalam melakukan kegiatan dakwah melalui kajian hadits tarbawi yang terdapat dalam kitab Arba'in Ad-Da'awiyah, Teladan Aplikatif Dakwah Rasulullah.

\section{Hasil Diskusi}

Komunikasi persuasif yang dilakukan oleh Rasulullah Shallallahu 'Alaihi Wasallam terhadap kaum perempuan dapat kita lihat dalam sebuah hadits Rasulullah Shallallahu 'Alaihi Wasallam yang diriwayatkan oleh abu Sa'ad Al-Khudri :

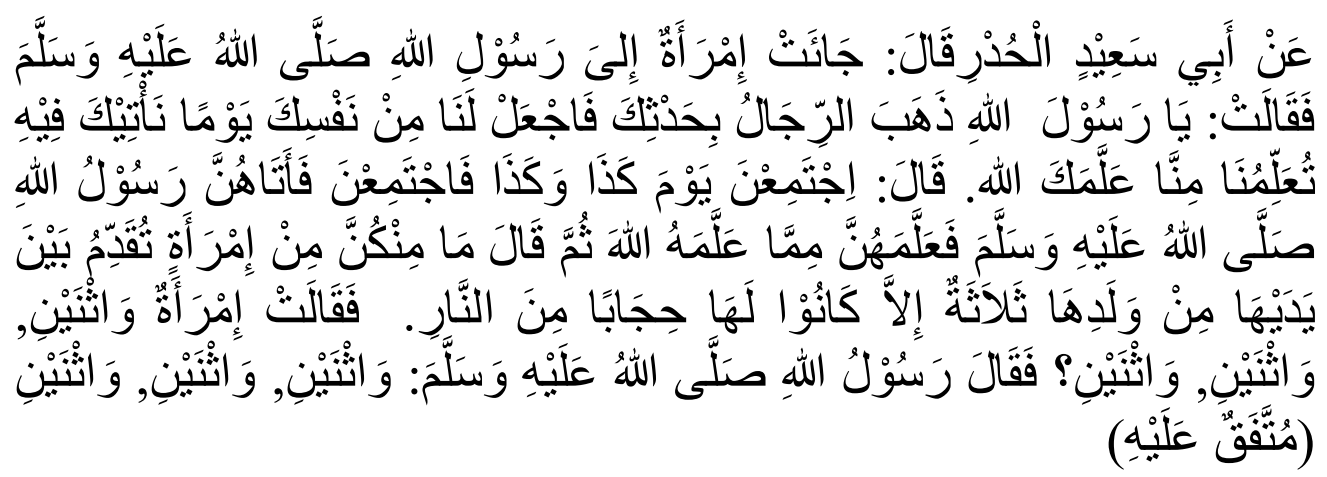

"Abu Sa'id Al-Khudri menuturkan, "Ada seorang perempuan datang kepada Rasulullah Shallallahu 'Alaihi Wasallam. Seraya berkata :"Wahai Rasulullah, kaum lelaki telah mengalahkan kami dalam menerima pelajaran darimu, maka tentukanlah untuk kami suatu hari yang kami akan mendatangimu dan engkau mengajarkan kepada kami apa yang diajarkan oleh Allah kepadamu". Beliau bersabda, "berkumpullah pada hari ini dan ini, di tempat ini dan ini." Setelah berkumpul, Rasulullah Shallallahu 'Alaihi Wasallam. Mendatangi mereka dan mengajarkan kepada mereka sebagian dari apa yang diajarkan oleh Allah Subhanahu Wata'ala kepada beliau, kemudian beliau bersabda, "Tidak ada seseorang perempuan diantara kamu yang ditinggal mati ketiga anaknya, melainkan hal itu akan menjadi penghalang baginya dari api neraka." Salah seorang dari mereka bertanya, "Wahai Rasulullah, bagaimana kalau dua 
orang anak?" (Perempuan itu mengulang pertanyaannya dua kali) lalu beliau bersabda, Dua orang anak, dua orang anak, dua orang anak". (HR. Bukhori dan Muslim) $)^{3}$

Hadits ini menunjukkan dengan jelas betapa Rasulullah Shallalahu 'Alaihi Wasallam memperhatikan pendidikan bagi kaum perempuan. Hal ini terlihat dari tuntutan Shahabiyah untuk menuntut ilmu dari Rasulullah Shallallahu 'Alaihi Wasallam dan bagaimana mereka memenuhi perintah beliau. Pendidikan untuk perempuan memiliki urgensi besar di dalam agama Allah. Di dalam Al-Qur'an dan As-Sunnah terdapat perhatian akan hal itu. ${ }^{4}$

\section{Menyikapi Motivasi Belajar Kaum Perempuan}

Sabda Rasulullah Shallallahu 'Alaihi Wasallam :

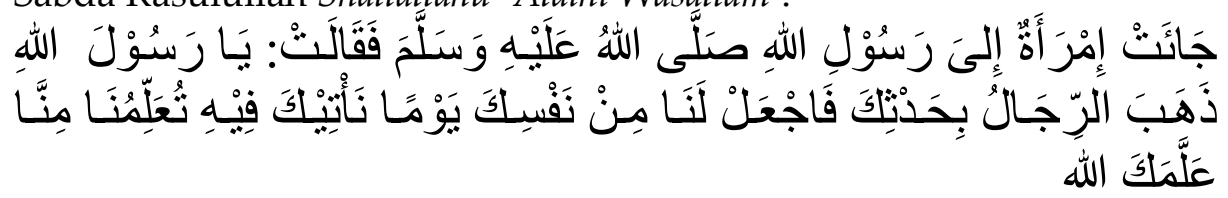

"Seorang perempuan datang kepada Rasulullah Shallalahu 'Alaihi Wasallam seraya berkata "Wahai Rasulullah, kaum lelaki telah mengalahkan kami dalam menerima pelajaran darimu, maka tentukanlah untuk kami suatu hari yang kami akan mendatangimu dan engkau mengajarkan kepada kami apa yang diajarkan oleh Allah kepadamu". ${ }^{5}$

Penggalan hadits ini menunjukkan motivasi belajar yang kuat pada diri kaum perempuan (Shohabiyah). Adanya motivasi belajar yang kuat pada diri perempuan, disebabkan oleh beberapa faktor sebagai berikut:

a. Kuatnya naluri kerinduan, kasih sayang, dan kelembutan pada diri perempuan'. Syeikh Yusuf Qordowi berkata : "Secara umum perempuan lebih besar atensinya terhadap agama dari pada kaum pria. Tampak sekali bahwa naluri kerinduan, kasih sayang, dan kelembutan yang di anugrahkan khusus kepada kaum

${ }^{3}$ HR. Bukhori dalam Shahih-nya Kitabul I'tisham, bab Ta'limin Nabiy ummatahu minarrijal wan nisa' (96/9/7310). Muslim dalam Shahih-nya Kitabul Birri Wash- shilah wal adab, bab fadhli man yamutu lahu walad fayahtasibuh (45/47/2633).

${ }^{4}$ Falih bin Muhammad bin Falih Ash-Shughayyir, Majelis Perempuan, Pesan dan Wasiat Rasulullah Kepada Kaum Perempuan, Jakarta : Darus Sunnah, Cet-1, 2008, h.25.

${ }^{5}$ HR. Bukhori dalam Shahih-nya Kitabul I'tisham, bab Ta'limin Nabiy ummatahu minarrijal wan nisa', 96/9/7310.

${ }^{6}$ Nursyam Fakhruddin, Syarah Arba'ain Da'awiyah, Surakarta : Bina Insani, 2006, h. 79 . 
perempuan telah dijadikannya lebih dekat kepada fitrah keagamaan dari pada pria. Tidaklah mengherankan bila suratsurat pernyataan dari kaum ibu dan pemudi lebih banyak dan melimpah dari pada surat-surat pernyataan dari kaum pria dan pemuda." 7

b. Banyak permasalahan rutin yang dihadapi kaum perempuan seperti permasalahan haid, istihadhoh, hamil, nifas, dan menyusui serta permasalahan-permasalahan keluarga yang belum mereka ketahui kedudukan hukumnya. Karena banyaknya permasalahan yang dihadapi, kaum perempuan terdorong untuk belajar dan mengkaji hukum-hukum agama yang berkaitan dengan rutinitas mereka, meskipun sebenarnya mereka merasa malu untuk menyatakan semua itu. ${ }^{8}$ Sebagaimana Aisyah Radhiallahu 'Anha berkata: "Sebaik-baik kaum perempuan adalah kaum perempuan anshar, rasa malu mereka tidak sampai mengahalangi mereka untuk memperdalam ilmu agama." (HR. Muslim) ${ }^{9}$

c. Kuatnya rasa takut terhadap pedihnya siksa api neraka pada diri perempuan. Sehingga sekecil apapun permasalahan yang dianggap berpotensi menyeretnya kedalam api neraka, mereka dengan segera menanyakannya kepada Rasulullah Shallallahu 'Alaihi Wasallam ${ }^{10}$.

Dr. Muhammad 'Utsman Najati mengatakan: "Rasa takut merupakan emosi yang penting dalam kehidupan manusia. Takut merupakan ungkapan emosi yang bersifat fitrah yang dirasakan oleh manusia pada situasi berbahaya atau dalam situasi yang mengancam keselamatan dirinya. Perasaan takut sangat bermanfaat bagi manusia karena perasaan ini akan mendorong manusia untuk menjahui situasi-situasi yang berbahaya maupun keadaan-keadaan yang bisa mengakibatkan kebinasaan. Hal ini sebagaimana juga manusia mampu mengantisipasi ancaman dengan berbagai cara ketika ada serangan yang tertuju pada

${ }^{7}$ Al-Qhordhowy Yusuf, Muqodimah fatwa Fatwa Kontemporer, Jakarta : Gema Insani press, Jilid I, 1995, h.53.

${ }^{8}$ Nursyam Fakhruddin, ... h.79.

${ }^{9}$ HR. Bukhori (1233), Muslim (834), Ahmad (3/215), Ibnu Abi Ashim (3084) dalam Al-Ahad Wa al-matsani, dan Al-Baihaqi (2/457) dalam sunan Al-Kubra.

${ }^{10}$ Nursyam Fakhruddin, ... h. 79. 
dirinya. Rasa takut yang paling penting dan paling bermanfaat dalam kehidupan manusia adalah takut kepada azab Allah Subhanahu Wata'ala. Rasa takut inilah yang memacu manusia untuk berpegang teguh pada kewajiban-kewajiban agama, melaksanakan segala sesuatu yang di ridhoi Allah Subhanahu Wata'ala. Dan menjahui larangan-Nya serta enggan untuk mengerjakan perbuatan dosa maupun maksiat"11. Dalam AlQur'an Allah juga telah menegaskan:

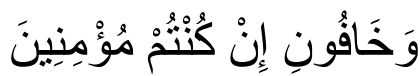

"Tetapi takutlah kepada-Ku, jika kamu benar-benar orang yang beriman." (QS. Ali-Imran : 175) ${ }^{12}$

d. Sikap kritis, jeli, dan perfek dalam berbagai urusan sehingga perempuan seringkali menuntut kejelasan dalam setiap urusan. Hal inilah yang mendorongan mereka untuk banyak belajar dan mengkaji perkara-perkara agama. ${ }^{13}$ Sebagaimana dapat dilihat dalam sebuah hadits yang diriwayatkan oleh Imam Bukhori dan Muslim yang artinya:

Abdullah bin Mas'ud berkata : "Allah melaknat perempuanperempuan yang mentato dan yang meminta ditato, yang mencabut alisnya, yang mengikir gigi depannya, untuk kecantikan dan yang mengubah ciptaan Allah." Ketika perkataan ini sampai ke telinga salah seorang perempuan dari bani Asad yang bernama Ummu Ya'qub, Ia berkata : "Telah sampai kepadaku bahwa engkau melaknat perempuan ini dan itu." Ibnu Mas'ud berkata : "Bagaimana aku tidak melaknat apa yang dilaknat oleh Rasulallah dan dilaknat dalam kitab Allah?!" Perempuan itu berkata : "Sungguh aku telah membaca seluruh Al-Qur'an, namun tidak aku tidak menemukan apa yang kamu katakan." Ibnu Mas'ud berkata : "Sungguh jika kamu serius membaca, niscaya kamu akan menemukan firman Allah : "Apa yang di bawa oleh Rasul kepadamu, maka ambillah, dan apa-apa yang dilarangnya maka tinggalkanlah." Ia menjawab, "Benar"

${ }^{11}$ Najati Muhammad Utsman, Psikologi Dalam Tinjauan Hadits Nabi SAW, Jakarta : Muttaqiim, Cet-I, 2003, h.126-127.

${ }^{12}$ Al-Qur'an dan terjemahannya, Yayasan Penyelenggara Penerjemahan, Bandung : Diponegoro, Cet-10, 2006, h.73.

${ }^{13}$ Nursyam Fakhruddin, ... h. 78 
Ibnu Mas'ud berkata : "Sesungguhnya Rasulullah Shallallahu 'Alaihi Wasallam. Telah melarangnya." Ia berkata : "Tetapi aku melihat istri kamu melakukannya." Ibnu Mas'ud berkata : "Pergi dan lihatlah sendiri" lalu perempuan itu pergi untuk melihat, ternyata tidak menemukan sedikitpun dari apa yang disangkanya. Ibnu Mas'ud berkata : "Seandainya begitu, niscaya aku tidak akan mengumpulinya (Istrinya). (HR. Bukhari dan Muslim $)^{14}$

\section{Perlakuan Khusus Kepada Kaum Perempuan Dalam Proses Dakwah}

Beliau Rasulullah Shallallahu 'Alaihi Wasallam bersabda :

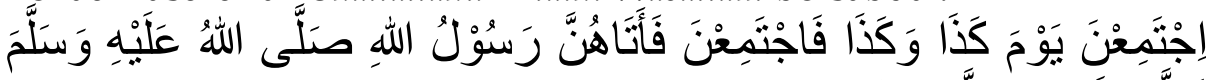

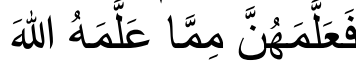

"Berkumpullah pada hari ini dan ini, di tempat ini dan ini." Setelah berkumpul, Rasulullah Shallallahu 'Alaihi Wasallam. Mendatangi mereka dan mengajarkan kepada mereka sebagian dari apa yang diajarkan oleh Allah kepada beliau". ${ }^{15}$

Penggalan Hadits ini menunjukkan adanya perlakuan khusus terhadap kaum perempuan dalam proses dakwah dan tarbiyah. Rasulullah Shallallahu 'Alaihi Wasallam menetapkan waktu dan tempat yang khusus untuk mendidik mereka. Tindakan beliau ini mengandung hikmah yang besar diantaranya :

a. Untuk mengantisipasi agar tidak terjadi Ikhtilat (campur-baur antara laki-laki dan perempuan) dan pandangan yang diharamkan serta fitnah yang diakibatkannya. ${ }^{16}$ Hal ini sebagaimana yang disabdakan Rasulullah dalam haditsnya yang diriwayatkan oleh Abdullah Ibnu 'Abbas :

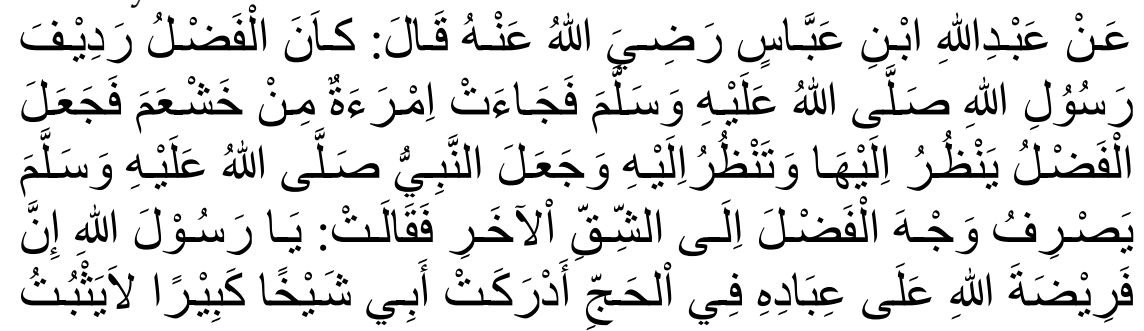

${ }^{14}$ Nursyam Fakhruddin, ... h. 80

${ }^{15}$ HR. Bukhori dalam Shahih-nya Kitabul I'tisham, bab Ta'limin Nabiy ummatahu minarrijal wan nisa', 96/9/7310.

${ }^{16}$ Nursyam Fakhruddin, ... h. 81 


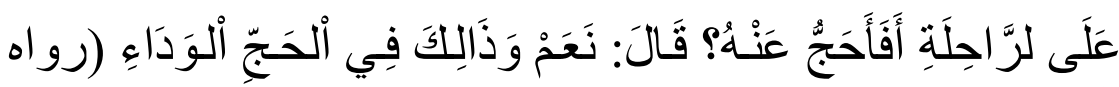 \\ (البخاري)}

"Ibnu Abbas berkata, 'Ketika Fadhl sedang duduk berboncengan di belakang Rasulullah, datang seorang perempuan dari khats'am. Fadl memandang perempuan itu, dan perempuan itu juga memandang fadhl, lalu Nabi Shallallahu 'Alaih Wasallam memalingkan wajah fadhl ke arah yang lain. Perempuan itu bertanya, "Wahai Rasulullah sesungguhnya Allah telah mewajibkan haji untuk hamba-hambanya-Nya, sedangkan ayahku sudah lanjut usia dan tidak mampu melakukan perjalanan, bolehkah aku berhaji untuknya? Nabi saw menjawab "Ya" (HR. Bukhari dan Muslim) ${ }^{17}$

b. Agar perempuan lebih terbuka membahas berbagai permasalahan yang tidak mungkin untuk mereka bicarakan dalam forum umum, disebabkan rasa malunya yang sangat dominan. ${ }^{18}$ Sebagaimana yang di sabdakan Rasulullah Shallallahu 'Alaihi Wasallam dari Ummu salamah :

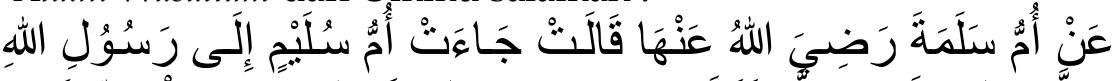

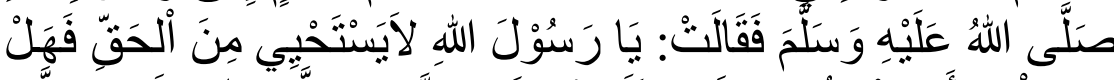

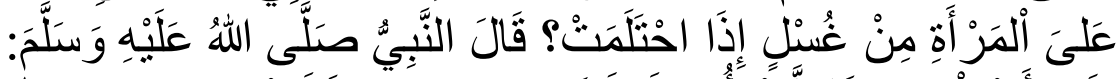

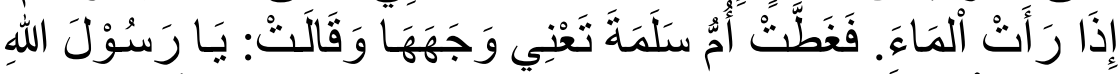

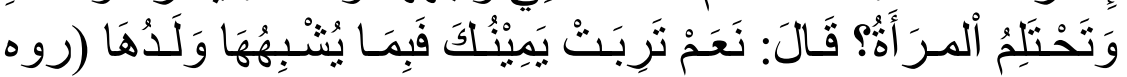

(البخري)

Artinya : "Ummu Sulaim mendatangi Rasulullah Shallallahu 'Alaihi Wasallam seraya berkata : "Wahai Rasulullah, sesungguhnya Allah tidak malu terhadap kebenaran, maka apakah ada kewajiban mandi bagi perempuan apabila mimpi? Nabi saw. Menjawab : "Ya, apabila ia melihat air mani." Lalu Ummu Salamah menutup wajahnya seraya bertanya : "Wahai Rasulullah apakah perempuan mengalami mimpi?" beliau menjawab : "Ya, kalau tidak, maka dari mana seorang anak bisa menyerupai ibunya." (HR. Bukhari) ${ }^{19}$

${ }^{17}$ HR. Malik (1/359), Ahmad (1/346,359), dan Bukhori (1513).

${ }^{18}$ Ibid.,

${ }^{19}$ HR. Bukhori (1/15), Malik (282/6121). 
c. Agar kewajiban-kewajiban rumah tangga tidak terlantar, seorang istri dan suami bisa menghadiri majelis-majelis ilmu dan melaksanakan kewajiban rumah tangga secara bergantian. Terutama bagi keluarga yang memiliki anak kecil atau berada di lingkungan yang tidak aman sehingga akan menjadi sasaran pencurian bila rumah ditinggalkan dalam keadaan kosong. ${ }^{20}$

d. Adanya perbedaan pendekatan, permasalahan, kecenderungan, dan kepentingan antara kaum laki-laki dan kaum perempuan. Sehingga kalau antara laki-laki dan perempuan di campur dalam suatu forum kajian, maka tidak bisa memberikan hasil yang optimal bagi keduanya. Karena sebagaimana dimaklumi bahwa semakin homogen para peserta forum kajian, maka akan semakin efektif dan mudah materi dan pendekatan yang di gunakan. ${ }^{21}$

e. Untuk menjaga hati para mad'u agar tetap ikhlas dalam menghadiri majelis ilmu. yaitu semata-mata untuk menuntut ilmu dan ridha dari Allah Subhanahu Wata'ala. Dan bukan untuk mencari perhatian lawan jenis atau tujuan lain yang kurang baik. $^{22}$

\section{Strategi Komunikasi persuasif Rasulullah Shallallahu 'Alaihi Wasallam Dalam Berdakwah kepada Kaum Perempuan.}

Kemudian sabda Rasulullah Shallallahu 'Alaihi Wasallam :

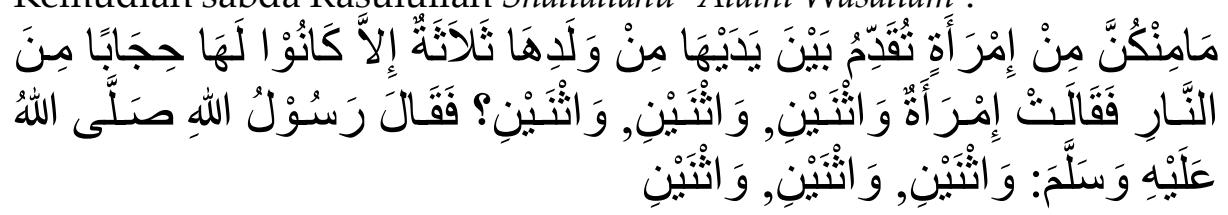

“Tidak ada seseorang perempuan diantara kamu yang ditinggal mati ketiga anaknya, melainkan hal itu akan menjadi penghalang baginya dari api neraka." Salah seorang dari mereka bertanya, "Wahai Rasulullah, bagaimana kalau dua orang anak?" (Perempuan itu mengulang pertanyaannya dua kali) lalu beliau bersabda, Dua orang anak, dua orang anak, dua orang anak". ${ }^{23}$

${ }^{20}$ Ibid., h.82.

${ }^{21}$ Ibid.,

${ }^{22}$ Ibid.,

${ }^{23}$ HR. Bukhori dalam Shahih-nya Kitabul I'tisham, bab Ta'limin Nabiy ummatahu minarrijal wan nisa', 96/9/7310. 
Penggalan hadits ini menunjukkan betapa hebatnya metode Rasulullah Shallallahu 'Alaihi Wasallam yang patut kita teladani dan diterapkan dalam upaya dakwah kepada kaum perempuan. Diantara metode itu adalah :

a. Memilih tema yang tepat.

Kesalahan dalam memilih tema yang tepat saat memberi materi/ ceramah, akan berakibat pada kegagalan dakwah. Audiens tidak akan memberikan respon yang maksimal terhadap dakwah, sehingga target dakwah tidak bisa tercapai. Dalam hadits ini, Rasulullah Shallallahu 'Alaihi Wasallam Memilih tema yang tepat bagi kaum perempuan, yaitu kematian anak dan motivasi untuk bersabar dengan mengingat balasan surga yang akan didapatkan. ${ }^{24}$

b. Lebih banyak menyentuh perasaan dan emosi.

Perempuan lebih banyak menggunakan perasaan dan emosinya dari pada menggunakan nalar dan logika. Oleh karena itu, pendekatan pada mereka hendaknya lebih banyak menyentuh aspek perasaan dan emosi, dan meminimalkan pendekatan yang berbau logika. Dari hadits di atas Rasulullah Shallallahu 'Alaihi Wasallam. Menyentuh perasaan dan emosi perempuan dengan memaparkan kematian sang buah hati yang sangat disayangi dan balasan kebahagiaan bagi yang bersabar terhadap musibah ini. ${ }^{25}$

c. Menunjukkan sikap empati.

Rasulullah Shallallahu 'Alaihi Wasallam, menyadari bahwa diantara penderitaan terbesar seorang perempuan adalah kematian anak-anak yang telah lama ia dambakan, dikandungnya selama sembilan bulan, disusuinya selama dua tahun, dan diharapkan menjadi tulang punggung di hari tuanya nanti. Namun betapa pedihnya, ketika mereka harus pergi untuk menghadap Ilahi. Pupus sudah segala harapan yang digantungkan kepada buah hatinya. Karenanya, sebagai bentuk empati kepada kaum perempuan, Islam memberikan balasan surga kepada seorang perempuan yang di tinggal mati kedua anaknya. ${ }^{26}$

${ }^{24}$ Nursyam Fakhruddin, Syarah Arba'ain Da'awiyah, Surakarta : Bina Insani, Cet. 10, 2006, h.82.

${ }^{25}$ Ibid., h. 83 .

${ }^{26}$ Ibid., 
d. Memberi peluang kepada kaum perempuan untuk menawar. Salah satu sifat perempuan yang dominan adalah kebiasaan menawar.baik itu keika membeli atau diberi sesuatu. Oleh karena itu, Rasulullah Shallallahu 'Alaihi Wasallam, Sangat memahami kebiasaan ini sehingga beliau tidak langsung mengatakan "Tidak ada seorang perempuan diantara kamu yang di tinggal mati kedua anaknya." Tetapi beliau mengatakan : "Ketiga anaknya" dengan maksud memberikan kesempatan kepada mereka untuk menawar, sehingga lebih memuaskan batin mereka. Sama sekali hal itu tidak menunjukkan bahwa Rasulullah Shallallahu 'Alaihi Wasallam, mengubah hukum agama dikarenakan adanya penawaran dari seseorang sebab ketentuan syari'at tentunya tidak akan berubah hanya karena penawaran seseorang. ${ }^{27}$

e. Melakukan dialog, bukan sekedar monolog Dengan membuka forum dialog, kaum perempuan bisa mengajukan pertanyaan atau menyampaikan curahan hati mengenai segala permasalahan yang dihadapinya. Dialog ini akan membantu kaum perempuan dalam memahmi kebutuhan berbicara dan mendengar yang lebih banyak dari kaum laki-laki. Tidak adanya saluran yang positif untuk memenuhi kebutuhan ini akan mendorongnya untuk mencari saluran yang diharamkan seperti ghibah, ngerumpi, atau menggunjing orang lain. Dialog juga lebih menghidupkan forum kajian, memecahkan banyak permasalahan-permasalahan, dan menguatkan ikatan hati antara akivis dan obyek dakwahnya. ${ }^{28}$

f. Memberikan jawaban yang memuaskan terhadap berbagai permasalahan yang dilontarkan.

Jawaban Rasulullah Shallallahu 'Alaihi Wasallam di dalam hadits ini yaitu:"Dua orang anak, dua orang anak, dua orang anak." Yang diulang sebanyak tiga kali ini pasti akan mendatangkan kepuasan dan kemantapan bagi penanya yang memiliki harapan besar untuk mendapatkan jawaban yang sesuai dengan keinginannya. Terbukti, Ia mengulang pertanyaannya sampai dua kali. Jadi, seorang aktivis

\footnotetext{
${ }^{27}$ Ibid.,

${ }^{28}$ Ibid.,h.84.
} 
dakwah hendaknya mampu memberikan jawaban yang memuaskan, bahkan kalau bisa lebih baik dari yang diharapkan penanya. ${ }^{29}$

g. Menutup forum dakwah dengan ending yang baik, berkesan, dan memberikan motivasi kuat untuk komitmen terhadap agama.

Sebagaimana yang dilakukan oleh Rasulullah Shallallahu 'Alaihi Wasallam, ketika berdakwah kepada kaum perempuan, setelah menyampaikan pelajaran agama, beliau menutup forum dakwah dengan dialog singkat yang sangat berkesan dan membangun motivasi yang kuat pada diri mereka untuk komitmen terhadap ajaran Islam. ${ }^{30}$

Itulah beberapa strategi komunikasi persuasif yang diterapkan oleh Rasulullah Shallallahu 'Alaihi Wasallam ketika berdakwah kepada kaum perempuan yang memiliki keunikan dan keistimewaan berbeda dari komunitas masyarakat yang menjadi ojek dakwah seorang aktivis dakwah. Oleh karena itu, seorang aktivis hendaknya menerapkan kiat dan strategi ini agar berhasil dalam perjuangan dakwah yang di upayakannya.

\section{Simpulan}

Strategi komunikasi persuasif Rasulullah Shallallahu 'Alaihi Wasalam dalam berdakwah terhadap kaum perempuan dapat dilihat dari beberapa aspek diantaranya adalah:

1. Memilih waktu yang tepat. Dalam berdakwah kepada kaum perempuan harus bisa menyesuaikan antara waktu dan tempat untuk menyampaikan materi, sehingga dakwah mudah untuk diterima,

2. Memberikan peluang kepada kaum perempuan untuk berdialog berupa pertanyaan atau curahan isi hati,

3. Lebih banyak menyentuh perasaan dan emosi. Karena target dakwah pada perempuan terletak pada emosi dan perasaannya jangan terlalu mengedepankan logika,

4. Menunjukkan sikap empati,

5. Melakukan dialog, bukan sekedar monolog,

6. Memberikan jawaban yang memuaskan terhadap berbagai permasalahan yang dilontarkan, 
7. Memberikan kesan dan motivasi kuat untuk komitmen terhadap agama.

\section{DAFTAR PUSTAKA}

Abdullah bin Walik Al-Syaikh, Tipudaya Musuh Terhadap Wanita, Jakarta : Akbar, 2001.

Al-Qhordhowy Yusuf, Muqodimah fatwa Fatwa Kontemporer, Jakarta : Gema Insani press, Jilid I, 1995.

Adnan Ath-Tharsyah, Menjadi Wanita Sukses dan Dicintai, Jakarta : Pustaka Al-Kautsar, Cet.III, 2005.

Al-Ghazali, Zainab, Al-Jubaili, Risalah untuk Wanita Muslimah, (Upaya Menggapai Kehidupan yang Lebih Baik), Jakarta : Najla Press, Cet.I, 2005.

Al-Qur'an dan Terjemahan, Yayasan Penyelenggara Penerjemahan, Bandung : Diponegoro, Cet-10, 2006.

'Abdul Latif bin Hajis Al-Ghomidi, 100 Dosa Wanita yang Diremehkan Wanita, Solo : Al-Qowam, Cet-V, 2001.

Afandi Basri, Beberapa Percikan Jalan Dakwah, Surabaya : Fakultas Dakwah Surabaya, 1984.

Al-Hashimi Muhamad Ali, Kepribadian Wanita Muslimah, Riyad : International Islamic Publising House, 2006.

As-Sayyid Majdi Fathi, Wanita Bertanya Nabi Menjawab, Jakarta : Pustaka AlKautsar, Cet-I, 2003.

Akram Ridha, , Tanggung Jawab Wanita Dalam Rumah tangga, Jakarta : Amzah, Cet-I, 2005. Al-Banna Hasan, Tipe Wanita Muslimah, Jakarta : Cendikia, CetI, 2005.

Cet.I, 2004.

Barakat Muhammad, , Pria dan Wanita dalam Satu Gerbong, Jakarta : Pustaka Al-Kautsar, Cet.I, 2005.

Departemen Pendidikan dan Kebudayaan, Kamus Besar Bahasa Indonesia, Jakarta : Balai Pustaka, Cet-III, 1990

Effendi H. Lalu Muchsin, Psikologi Dakwah, Jakarta : kencana, Cet-I, 2006.

Falih bin Muhammad bin Falih Ash-Shughoyyir, Majelis Wanita, Jakarta :

Darus Sunnah, 2008. 
,Faizah, Effendi H. Lalu Mukhsin, Psikologi dakwah, Jakarta : Kencana, Cet I, 2006.

Ghozali M. Bahri, Konep Ilmu Menurut Al-Ghazali Suatu Tinjauan Psikologik Pedagogik, Jakarta : Pedoman Ilmu Jaya, 1991.

Haya binti Mubarok Al-Barik, Ensiklopedi Wanita Muslimah, Jakarta : Darul Falah, Cet-16, 2008.

Hasanuddin H., SH, Hukum Dakwah, Tinjauan Aspek Hukum dalam Berdakwah di Indonesia, Jakarta : Pedoman Ilmu Jaya, 1996.

Cet-V, 2000.

H. Arifin M., Psikologi Dakwah, Jakarta : Bumi Aksara,

Ikhsan M., "Islam Memulyakan Kedudukan Wanita", dalam http/hati.unit.itb.ac.id?/p=51.

Jibriel Abu Muhammad AR, Ciri dan Fungsi Wanita Shalilah, Ar-Rahmah Media Publising, 2006.

Koentjaraningrat, Metode Penelitian Masyarakat, Jakarta: PT. Gramedia, CetVII, 1985.

Munawwir Ahmad Warson, Al-Munawwir, Kamus Arab Indonesia, Yogyakarta : Pustaka Progressif, Edisi-II, 1984.

Nurdin A. Fauzie, Wanita Islam dan Transformasi Sosial Keagamaan. Yogyakarta : Gema Media, cet I, 2009.

Nurdin A. Fauzie, Pemberdayaan Da'I dalam masyarakat lokal, Yogyakarta : Gema Media, Cet-I, 2009.

Nursyam Fakhruddin, Syarah Arba'ain Da'awiyah, Surakarta : Bina Insani, Cet-10, 2006.

Najati Muhammad Utsman, Psikologi Dalam Tinjauan Hadits Nabi SAW, Jakarta : Muttaqiim, Cet-I, 2003.

Nur, Muhammad, Seni Nasyid Sebagai Methode Dakwah Islam (Sebuah Kajian Teoritis), 1429 H / $2008 \mathrm{M}$.

Partanti Pius A, Al Barri M. Dhlan, Kamus Ilmiah Populer, Surabaya : Arloka, 1994.

Sa'dawi Amru Abdul Karim, Wanita dalam Fiqih Yusuf Al-Qhordhowy, Jakarta : Pustaka Al-Kautsar, Cet-1, 2009.

Suparta H. Munzier, H. Harjani Hefni, Metode Dakwah, Jakarta : Kencana, Cet-2, 2006.

Syukir Asmuni, Dasar-Dasar Strategi Dakwah Islam, Surabaya : Al Ikhlas, 1983.

Said Bin Ali Al-Qahthani, Dakwah Islam Dakwah Bijak, Jakarta :

Gema Insani Press, 1994. 
Suryabata Sumardi, Metode penelitian, Jakarta : Raja Grafindo Persada, 1993.

Umar Ar-Rawi Ahmad, Wanita-Wanita Sekitar Rasulullah, Jakarta : Akbar Media Eka Sarana, Cet-I, 2009.

Yasmin Ummu, Materi Tarbiyah,Panduan kurikulum bagi Da'i dan Murabbi, Solo : Media Insan Press, 